\title{
Mechatronics over time: 12 years of creative experiences in Ecuador
}

\author{
Verdugo Cabrera Alexandra, Rivera Rojas Henry, \\ Escobar Carvajal Luis, Mejía Campoverde Paul, \\ and Loza Matovelle David \\ Universidad de las Fuerzas Armadas - ESPE, Ecuador, adverdugo@espe.edu.ec, herivera@espe.edu.ec, \\ lfescobar@espe.edu.ec, phmejia@espe.edu.ec,dcloza@espe.edu.ec
}

\begin{abstract}
The present article present the evolution over time that Mechatronics education has undergo throught 12 years of experience. It analyzes the study methods, since its beginnings up to the projected actual state. The main analysis is done against the Grimheden model that shows the synergistic nature of mechatronics, and compare against the evolution in the curricular design in Universidad de las Fuerzas Armadas ESPE, three stages are analyzed because of the three major curricular design changes that have taken part during 12 years. In base of the three curricular designs and overlapping them with the Grimheden model a comparison is stablished for two stages in the carrer, first year and fourth year, for first year the subject of Mechatronics engineering Introduction is observed and for fourth year the subject Mechatronic Instrumentation is taken. Finally results and conclusion from this analysis are portrayed.

Index Terms-Mechatronics education, Curricula design, Cyber-Physical Systems
\end{abstract}

\section{INTRODUCTION}

Mechatronics over time has suffer many changes in their concept and the way it is taught, especially in Undergraduate level, those changes had turn mechatronics in the field that is represented now. Scientific and technological knowledge have evolved by leaps and bounds during the last years, moreover in the teaching methods for engineering. Those changes had allowed to face challenges of the modern society to solving problems. Nowadays, knowledge and abilities required from an engineer are very different from what was required before, and in mechatronics there is a clear example of this behaviour.[1] Therefore, mechatronics is a igniter to find viable solution to cover the needs in society, industry, medicine, and other fields.

The concept of mechatronics was coined in the 80s, by Tetsuro Mori who was an engineer in Yaskawa[2]. Mori defined $\mathrm{m}$ echatronics a $\mathrm{s} t$ he $i$ ntegration o $\mathrm{f} m$ echanism of automatic control indispensable for the development of any intelligent machine.[3] After this start many From this concept, numerous definitions $\mathrm{h}$ ave $\mathrm{b}$ een $\mathrm{p}$ resented, such as those proposed by Rietdijk [4] or Craig [5] who refer to mechatronics as "synergistic combination of mechanic precision engineering, electronics, automatic control and systems for deign of products and processes" and "Sinergistic integration of physical systems, electronics, control and computers trought design process from the start". What

Digital Object Identifier (DOI):

http://dx.doi.org/10.18687/LACCEI2019.1.1.451

ISBN: 978-0-9993443-6-1 ISSN: 2414-6390 allows to conceptualize mechatronics as the synergistic integration of the traditional mentioned engineering areas for the system-level design process.

Pointing out the main purpose of this paper is to expose three curricular designs defined in Universidad de las Fuerzas Armadas ESPE. The stages are studied to emphasize evidence of evolution of the mechatronics program throughout twelve years by the analysis different study cases. Finally, a result of a survey and interviews done to students and professors about mechatronics analysis is presented.

\section{Evolution of Mechatronic ENGINEERing's CURRICULAR DESIGN}

Under the conceptions of mechatronics, it is possible to analyze the evolution on the teaching methods by different study models. For the purpose of this paper it is better to take into account the model of Grimheden[6] and the model of Craig[5]. Those models are considered more relevant because their focus on education and teaching methods rather than industrial and standardization. There are other methods specialized in such subjects as the VDI2206[7] guideline, or the product design methodology[8], those models concentrate in the mechatronics design process and not in teaching methods for mechatronics engineering.

The model proposed by Grimheden[6] consist of a evolutionary process that start from a vizualization of mechatronics under a disciplinary view, with clear boundaries and few relations between the constitutive disciplines and finish with a visualization of a transdisciplinary approach as can be seen on Fig. 1[9], that shows six stages of evolution for mechatronics programs depending mainly in the approach to the concept and curricular designs. In the first stage, there are no interaction between disciplines, each one is focused in their own content and methods. In the second stage, in can be noticed multidisciplinary where, students can combine different lectures with different disciplines in order to extend their knowledge. Third stage, its mainly characteristic is to have a superposition of disciplines, here boundaries start to get lost and transfer of methods and contents is an everyday task. fourth stage, is based in the creation of new study plans, the development of an entire curricula focused on interdisciplinary, as result of those development a thematic identity is born in this kind of institutions. in Fifth stage the leadership is taken by professionals with a strong background

17 $7^{\text {th }}$ LACCEI International Multi-Conference for Engineering, Education, and Technology: "Industry, Innovation, And Infrastructure for Sustainable Cities and Communities", 24-26 July 2019, Jamaica. 
with inter and multidisciplinary education, hence diminishing the disciplinary contents and prioritizing the thematic view of mechtronics. The final stage is treat mechatronics completely as a thematic with boundaries gone between disciplines, this characteristic is mainly adopted by research centers.

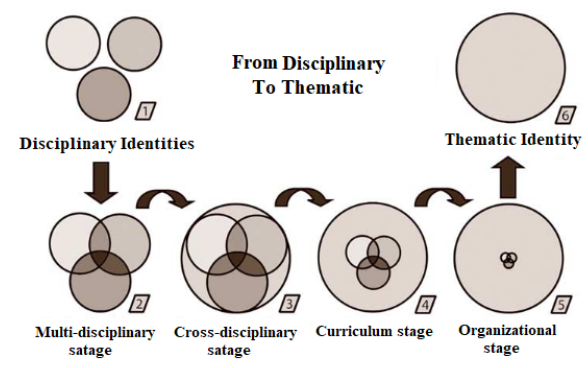

Fig. 1. The evolution of mechatronics' teaching using the Grimheden model. (1. Disciplinary identities; 2. Multi-disciplinary stage; 3. Cross-disciplinary stage; 4. Curriculum stage; 5. Organizational stage; 6. Thematic Identity). [10].

The Craig model referred by Aquino[19] points out that mechatronics implies a new and defined disciplinary field. It defines as an autonomous body backed up by the areas that had presided by means of integration in two models technical-scientific. It clarifies that it is common to believe that mechatronics is the sum of diverse engineering areas when in reality is the synergistic combination of pointed areas as shown in Fig. 2. The models of integration that Craig present are referred by Alvarez [18] in his analysis and represent the horizontal and vertical integration. The horizontal model pose that the synergistic interaction of disciplines has given way to creation of recognized engineering areas, research areas and even more technological innovations[20]. In the vertical model it is mentioned that the evolution of mechatronics is given by two factors: modern technologies and organizational knowledge.

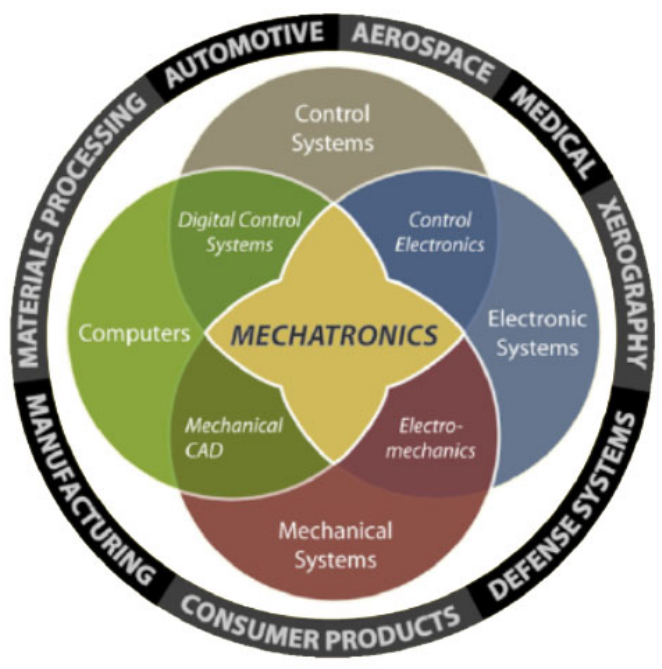

Fig. 2. Mechatronics model by Craig. [11].
The evolution of the curricula in the University can be analyzed by means of the Grimheden model. As mentioned before there are 3 curricular designs. The first, started in 2006 with the creation of the undergraduate program of Mechatronics Engineering. The second, was proposed as an improvement resulting of the analysis of the first graduated in 2012, it started in 2012 as well. This curricula was based on a competences design methodology, here final objectives of every lecture and moreover for the entire curricula were implanted some examples of final competences are "Design machines and components integrating mechanics, electric and electronic criterion with computer assisted methods.", "Automate machines and manufacturing processes, supervise production processes, assembly and testing machine and equipment." The third curricular design is the one that is executing nowadays since 2017. this last design poses an epistemologycal horizon to follow Industry 4.0 thought Cyber-Physical Systems due the recent tendency of reorganize and modernize education. That is why this last curricula is the start of a systemic curricula[12]. The tendency is clearer in the case of technology related studies, hence each day there are new advances that revolutionize the world, the way of living, making a priority for universities to renovate or extinguish. The last design was done mainly because there was a change in the politics of Ecuador, where standardization of education had an active role and high priority.

\section{A. First Curricular Design}

The first curricula was the formal expression of the structure and organization of the first studying plans, it considered the government guidelines and the objectives of the strategic planning of the University. The structure included mainly four kinds of lectures based on: mechanics, Electronics, ICTs and Mechatronics; Such contents grouped knowledge that let students to be prepare for the future. The program in the first year received 315 students in the first year, becoming one of the programs with higher demand in the University.

In order to get a balanced program a logic net of contents was developed, here the contents of lectures were classified by different areas as can be seen in Table I, [13]. Here it can be seen that $27.1 \%$ is represented by the Mechanics area with subjects as: Statics, Dynamics, Mechanism, among others. The $23.9 \%$ belongs to subjects of electronics as: Circuits, Basic electronics, Instrumentation, among others. and only $4.9 \%$ belong to ICTs as: Computers, programming. Being those three the main areas in the professionalization stage. In the same way, it can be seen that only the $14.2 \%$ contents are clearly recognized as Mechatronics in lectures as: Introdution to Mechatronics, Mechatronics Instrumentation, Mechatronics Design, among others. making this curricula primarily mechanic.

From the data collected in Table I, it can be inferred that

$1^{\text {th }}$ LACCEI International Multi-Conference for Engineering, Education, and Technology: "Industry, Innovation, And Infrastructure for Sustainable Cities and Communities", 24-26 July 2019, Jamaica. 
TABLE I

Subjects and class hours by area (2006)

\begin{tabular}{|l|l|l|l|}
\hline Area & Subjects & Class hours & Percentage \\
\hline Mechanics & 15 & 67 & $27.1 \%$ \\
Electronics & 14 & 59 & $23.9 \%$ \\
ICTs & 3 & 12 & $4.9 \%$ \\
Mechatronics & 10 & 35 & $14.2 \%$ \\
Social - Humanistic & 6 & 15 & $6.1 \%$ \\
Physics - Chemistry & 3 & 17 & $6.9 \%$ \\
Maths & 7 & 35 & $14.2 \%$ \\
Other & 3 & 7 & $2.8 \%$ \\
\hline
\end{tabular}

the first iteration of mechatronics curricula was born as a necessity from the mechanics program in order to deepen their knowledge in the electronics area. Such analysis make evident the multidisciplinary approach for the first curricula design. Figure 3 shows that the main focus on this design was to combine different disciplines in order to enlarge the capacities of the mechanics program students. Making a clear differentiation of mechanics, electronics and ICTs.

A clear example of the tendency in this stage were the titulation projects. Those projects traditionally had a strong component of mechanic design against other principles and methods. The projects were usually implementation or re powering of machines where mainly mechanics were involved and the electronics and control systems were in the background not as a synergistic design, additionally in those works almost never a clear guide for mechatronics design was followed.

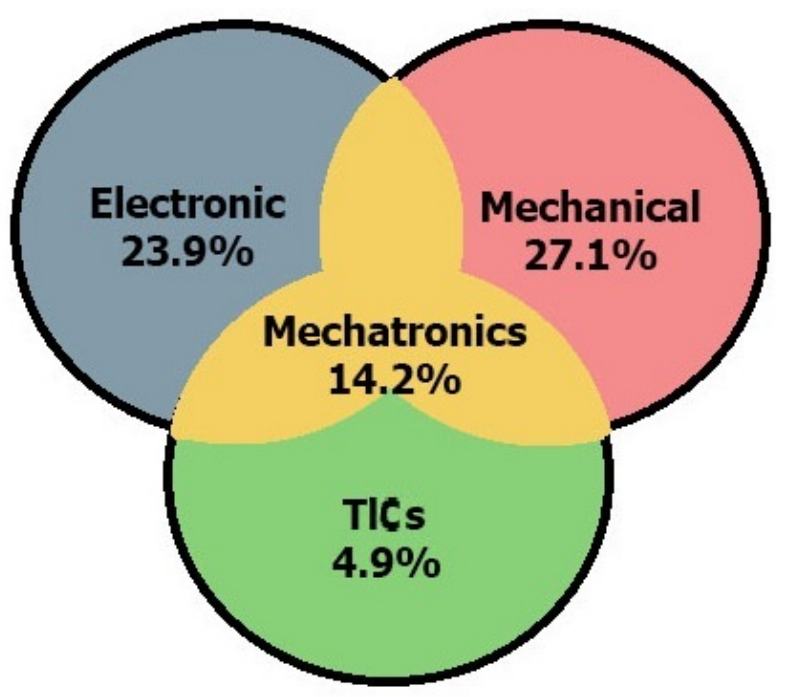

Fig. 3. First Curricular Design.

\section{B. Second Curricular Design}

The second curricula consist of a design based in competences[16]. The formation based in competences imply big challenges for the University in general. One of the main challenges was the projection of demand for the productive and service sectors, as the incorporation of professional practices as a key aspect of the formation. With the first generation of graduate students in 2012, there was a chance to close a loop and evaluate the professionals that the program was offering to the demands of local professionals specially. Here it was detected the need to take into account in the curricular design subjects that integrate knowledge from different disciplines and the need to have more professors with a multi and interdisciplinary formation. Again an analysis of logic net was used and a new product was created, while the core of mechatronics was conserved more interdisciplinary subjects were developed as shown in Table II as well in Figure 4 it can be seen that 27.3\% correspond to subjects in the Mechanics area as: Welding, Vibrations, Machine deisgn, among others. The 21.6\% subjects were related directly with Electronics as: General electronics, Electric machines, Programable Logic Controlers, among others. and only $1.8 \%$ were specifically TICs area as: Programming, Operative systems and networks. In the same way it can be noticed that $15.2 \%$ correspond to Mechatronics as: Introduction to mechatronics engineering, Mechatronics instrumentation, robotics, among others. In a very similar way as the first design approximately the $30 \%$ correspond to physics, math, chemistry and humanistic.

In Figure 4 it can be noticed the evolution of the program, the main difference lays in the creation of so called integration projects, there were three integration projects during the program where mechatronics was addressed from an interdisciplinary point of view and became a priority to recognize mechatronics as a thematic in itself. The ideology of the integration projects was to use the knowledge of every formation stage and translate it into practice making the synergy effect clear for the students. In this subjects the knowledge of the student was put on test as well as the knowledge of the professor, since many of the professors had strong backgrounds on mechanics or electronics mainly, in those subjects problems were planted and during a semester a solution has to be developed. Another important change that took place in this design was the need to make projects related to reality in many subjects where inter and multidisciplinary were boarded.

Another advantage from the integration projects was that many of them were a prior work to the titulation projects for students, in the last stages a clearer distribution of work was recognized and projects were developed with the projection of integrate different disciplines, stages and the most daring students started to propose research ideas with new technologies. It is so works as [14] and [15] where research of students for the future development of the program were established. 
TABLE II

Subjects and class hours by area (2012)

\begin{tabular}{|l|l|l|l|}
\hline Area & Subjects & Class hours & Percentage \\
\hline Mechanics & 17 & 70 & $27.3 \%$ \\
Electronics & 13 & 55 & $21.6 \%$ \\
ICTs & 3 & 18 & $7.0 \%$ \\
Mechatronics & 12 & 39 & $15.2 \%$ \\
Social - Humanistic & 7 & 15 & $5.9 \%$ \\
Physics - Chemistry & 3 & 17 & $6.6 \%$ \\
Maths & 7 & 34 & $13.3 \%$ \\
Other & 3 & 8 & $3.1 \%$ \\
\hline
\end{tabular}

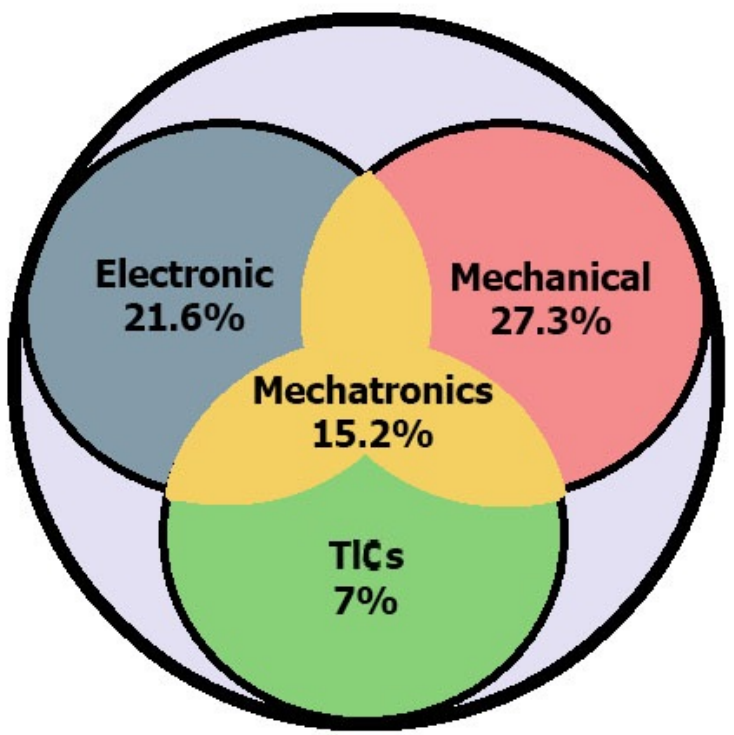

Fig. 4. Second Curricular Design

\section{Third Curricular Design}

The third curricula is the one that is active nowadays, since 2017[17]. As well as the previous curricular designs the main disciplines still have a strong component in the program. Furthermore, the synergy principle is enforced from the start of the program, in this program it is clear that a major component of the inter and trans disciplinary approach is taken into account, that is why the mechatronics component has grown from $15.2 \%$ to a $20.3 \%$ meanwhile electronic and mechanical components had small variations, another interesting change is the inclusion of subjects as Introduction to Cyber-Physical Systems, Intelligent Manufacturing and Artificial Intelligence as mandatory subjects for all the students.
TABLE III

Subjects and class hours by area (2016)

\begin{tabular}{|l|l|l|l|}
\hline Area & Subjects & Class hours & Percentage \\
\hline Mechanics & 16 & 54 & $24.9 \%$ \\
Electronics & 13 & 48 & $22.1 \%$ \\
ICTs & 1 & 4 & $1.8 \%$ \\
Mechatronics & 13 & 44 & $20.3 \%$ \\
Social - Humanistic & 5 & 10 & $4.6 \%$ \\
Physics - Chemistry & 3 & 17 & $7.8 \%$ \\
Maths & 7 & 34 & $15.7 \%$ \\
Other & 2 & 6 & $2.8 \%$ \\
\hline
\end{tabular}

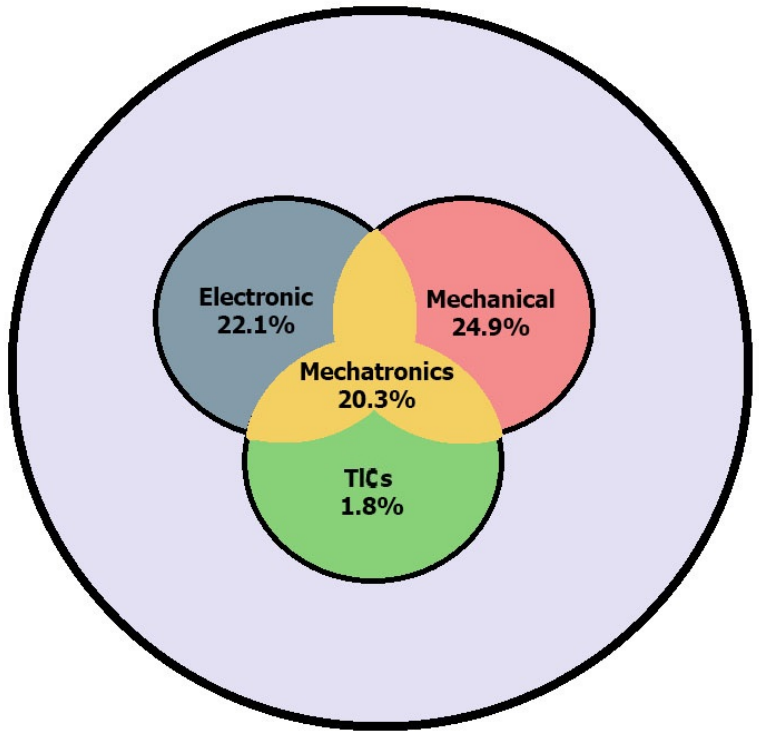

Fig. 5. Third Curricular Design

In Figure 5. it can be seen the tendency of the program to trans disciplinary design,inasmuch as the three principal components of mechatronics there are much more mechatronics specific subjects and moreover there is one integration subject in each semester starting on the professionalization stage. In rder to accomplish the objectives a new structure of practical experience is proposed where more than a third ot he time expended by the student needs to be in practical projects or guided practice, therefor pushing the system for students to reach new horizons related with technology as: IoT, Industry 4.0, Cloud Robotics. Such knowledge is already inserted as a transverse component thorough the integration subjects that are: Introduction to Cyber-Physical Systems, Machine design, Computer aided Manufacturing, Mechatronic systems, among others. Even so, these can be contrasted with practices and research projects.

Since the second curricula many subjects have the view of integration, more now the expectations are to enlarge this experience and have more hands on experience on the design and development process of mechatronic systems to obtain Cyber-Physical Systems, the new final projects are expected to contain more trans disciplinary components. Such works have to consider the principles of mechatronics and application to research. 


\section{STUDY CASES}

Since 2006, the year in which started the program, the development of projects where the student recognizes and relates each of the disciplines that make up mechatronics has been emphasized that is what is recognized as multidisciplinary. With the first actualization of curricula in 2012, a evolution on the model was pursued to integrate contents of disciplines in one concept, that is what is recognized as interdisciplinary. this objective was fulfilled at a large degree by the inclusion of integration projects where students explore concepts and methodologies to solve problems using mechatronics concepts. With the last upgrade of the curricula a new evolution is pursued, searching that in addition to integration projects, key subjects contain the principles for a synergy development of products and processes, those principles cross the design vertical and horizontal making it trans disciplinary. In order to evidence the advance during the time three different case of study were analyzed, each one for each curricula.

In order to pose the case of study two stages of formation were considered, the first one in the first year, and the other in fourth year. In the initial stage the subjects chosen were the ones that introduce the student to the principles of mechatronics, those subjects are Introduction to mechatronics engineering in the first iteration, Integration Project $I$ in the second one and Fundamentals for Mechatronics engineering in the last one. In the superior stage the subjects chosen were the ones that are a backbone in the curricula and are key to accomplish the knowledge of and purpose of the program, in the first and second iteration Mechatronics instrumentation were chosen due the evolution shown by the students while in the last one was Introduction to Cyber-Physical Systems. The cases of instrumentation were chosen by the evolution of the students during the years and since the third iteration of the curricula is still in second year there are not yet a project developed in the chosen subject but, the projection of the subject make it easy to compare since the main purpose of the subject is to develop abilities in the students to go from mechatronic systems to CPS, using technologies such as IoT, Industry 4.0 principles, cloud robotics to name few.

\section{A. Case 1 Curricula 2006-2010}

The first case of study is the contribution of the subject Introduction to Mechatronics Engineering. The general theme that was learned was based on the manual of mechatronic engineer which establish mechatronic under five fundamental pillars that are: Modeling of physical systems, sensors and actuators, systems and controls, logic systems and computation and data acquisition[21]. The teaching outcomes let familiarize the student with the principal concepts that are learned during the program as sensors, actuators, signals, controls and modelling, the laboratories where the different subjects are teach and the relation between the constitutive disciplines of mechatronics. The final project of the subject was the creation of a prototype that gives a solution to a specific problem. This kind of prototypes is shown in Table IV.a, in this case a line follower was build.

Another subject of study was Instrumentation. Such subject had a more theoretical focus than practical, given by the limitation on the laboratories for its implementation. The expected results seek that the student recognize the components of each device the physical laws that govern their behaviour and more important followed the purpose that the student be able to characterize a sensor and their properties in order to calibrate, select and determine their operation. At the end of the subject a final project was pursued to assure that the student had assimilated the knowledge, the result of this project is shown in Table IV.d.

\section{B. Case 2 Curricula 2011-2016}

The second case of study is presented by analysing the subject of Integration Project I. The teaching outcomes followed were to integrate the knowledge aquired during the first year of the program in orfer to generate a project where all the disciplines and many of the principles learned are showed, one example of this kind of projects is the medicine dispenser presented in Table IV.b.

Another subject analyzed is Mechatronic Instrumentation. This subject was created due the necessity to deepen the knowledge of the mechatronics engineers in the instrumentation area. During the semester in the lectures one of the main topics is to learn to virtualize sensing tools and the creation of user interfaces. As result of the studies it was sought that the student integrate in a joint way all the knowledge acquired. The final project consisted in realize a prototype of process that take into account at least three variables to control, two of them analog and a third one digital. To show their competence the students are required to build a physic prototype of the selected process where the instrumentation is implemented, also they are required to do data acquisition an treatment to show all in a HMI. The interfaces let the user identify on a correct manner the controlled variables and the process that is executed in real time as shown in Table IV.e.

\section{Case 3 Curricula 2017-2022}

The third case of study is about the subject Fundamentals for Mechatronics Engineering, in this subject the starting point is to analyze systems as Lego Mindstorm or Tetrix Prime. During the semester a guided analysis is carried out to to emphasize in the transdisciplinarity of mechatronics. Furthermore, a examination to understand the input of each discipline is carried out. It is seen how Mechanics interact as structures stable and durable, electronics of each sensor and configuration of systems created, the control of each of the actuators, ICTs that allow the development of software 


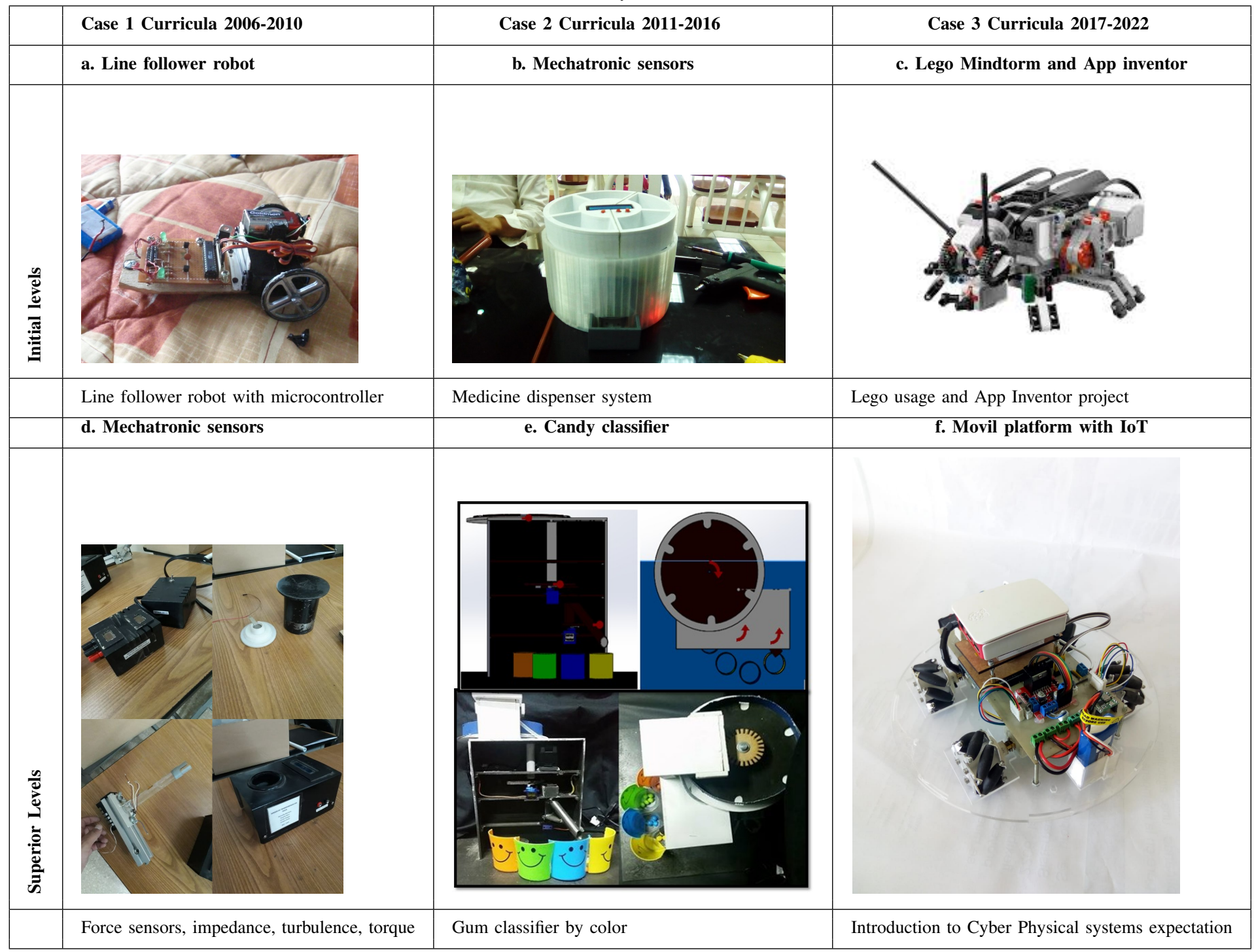

as Appinventor that is used to manipulate and monitor the system remotely. From this study it can be visualized how trough all the interactions a complex and modular system can be created with modularity in order to build different kinds of prototypes. The results of this subject is to exemplify the transdisciplinarity involved in mechatronics an example of prototype is presented in Table IV.c.

The last subject analyzed is Introduction to Cyber-Physical Systems. As learning outcomes is highly sujested that an interdisciplinary colaoration takes part between disciplines, the major change is that the systems developed in this subject need to have interconnnectivity, interoperativity, security and interactions in the cyberbetics field, a clear example is to be able to manipulate a system with IoT. as a possible final project the implementation of robotic platforms is presented in Table IV.f.

\section{Analysis}

From the case studies raised, the evolution of the career along the three curricular designs is well known. In the first case, the student was evaluated both theoretically and practically. the evaluation was carried out to ensure that the concepts taught were correctly assimilated. Within the practical part, the student's ability to provide a mechatronic solution that shows the different areas applied was evaluated. In the second case, it was analyzed how the student used the knowledge obtained to be able to properly select the type of sensor to be used in the various applications, for this the student should be able to identify the nature of each phenomenon.

With the first change of curricula in 2012, the way of evaluating was modified since the aim was for the student to

17 $7^{\text {th }}$ LACCEI International Multi-Conference for Engineering, Education, and Technology: "Industry, Innovation, And Infrastructure for Sustainable Cities and Communities", 24-26 July 2019, Jamaica. 
identify and define how all the areas of engineering that make up mechatronics were integrated. In the third case, it was taken into account how the students integrated the subjects they knew in order to solve the given problem. Similar to the fourth case, a system was employed where a court made up of dozentes from the specific areas of mechanics and electronics was responsible for evaluating the projects presented by the students. In this case, the demonstration of the interdisciplinarity of the race was sought.

In order to evaluate transdisciplinarity in the third mesh, the tutor examines that the students demonstrate the synergy existing in the various areas of mechatronics. In the fifth case, the student uses the lego or tetrix kits to generate a solution in which one can appreciate how the synergy of the different fields of mechatronics can solve the same problem in different ways. Finally, in the sixth case, it is expected to analyze how the use of new technologies generates an interrelation between the disciplines studied.

\section{IMPLEMENTATIONS AND RESULTS}

With the analysis of the case studies, an interview was conducted with 4 of the tutors who taught the previous subjects, and with the information obtained to analyze the evolution of the same, a test was applied to a group of students and graduates where the first question was to what mesh they belong and thus show their persecution of the race.

Several of the tutors not only taught one or two of the subjects analyzed in the case studies, but also others such as Industrial Robotics, Flexible Manufacturing Systems or Programming Logic Controllers, which allowed them to have a clearer vision of what transdisciplinarity implies inside the Mechatronics. It was asked what the tutor understands by Mechatronics and all the answers agreed that Mechatronics is a synergistic integration of several disciplines such as mechanics, electronics, and ICTs, based on the previous answer the question arose for students and graduates, What is your concept of Mechatronics ?. All the tutors agree that the correct way to familiarize the student with the concepts is through practice, so they always propose projects within their chairs as could be observed in the case studies, which is why the question arose for the students and graduates, have you done any projects that exemplify your concept of mechatronics? Finally, in interview 3 of the 4 tutors consider that it has an interdisciplinar approach within its chairs, which raises two questions for students and graduates. What knowledge do you consider most representative? and Considers that the career has a focus: multidisciplinary, interdisciplinary and transdiciplinary.

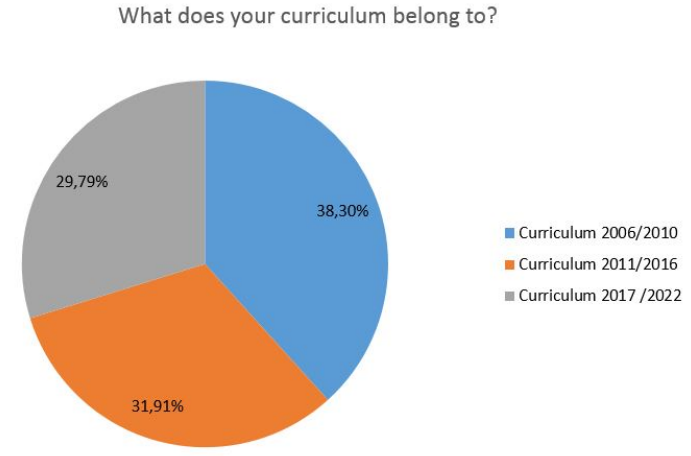

Fig. 6. First Question.

In the surveys of students/graduates there are 47 respondents of which $38.3 \%$ belong to the first mesh implemented in 2006 currently all of them graduates, $31.91 \%$ are in the mesh of 2012 among them are graduated, graduates and students of higher levels and the remaining $29.79 \%$ are studying the current mesh of 2017 , in the initial levels $1,2,3$.

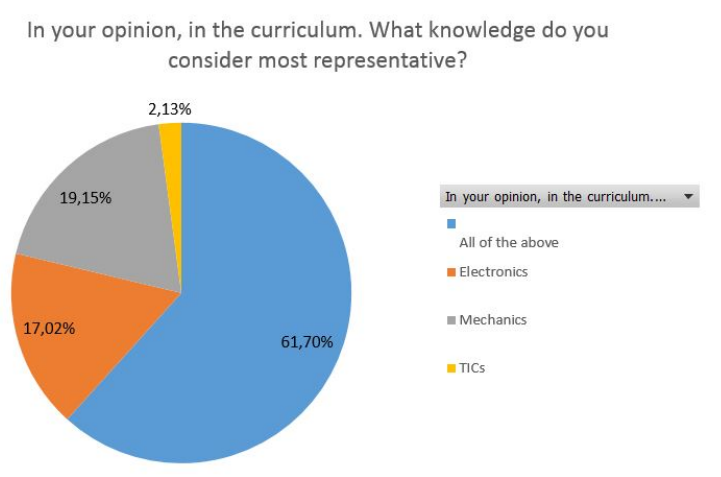

Fig. 7. Second Question.

In this group $61.70 \%$ believe that mechatronics is an integration of the areas of mechanics, electronics and ICTs or in their own words: There is knowledge of the aforementioned branches, however there are no subjects that mostly integrate these branches , $19.15 \%$ believes that it has a tendency to the mechanical area this percentage was in total belonging to students of the first mesh, this is because this surveyed part has used mostly in their professional life the mechanical knowledge, $17.4 \%$ considers that electronics is the orientation of the curriculum this is due to the fact that the percentage of respondents are mostly in the third curricula or attended the first, keeping in mind ideas such as mechatronics without electronics is simply mechanical according to the data obtained and the $2.2 \%$ considers that it has an orientation to ICT. 
Which one considers the most accurate concept of Mechatronics?
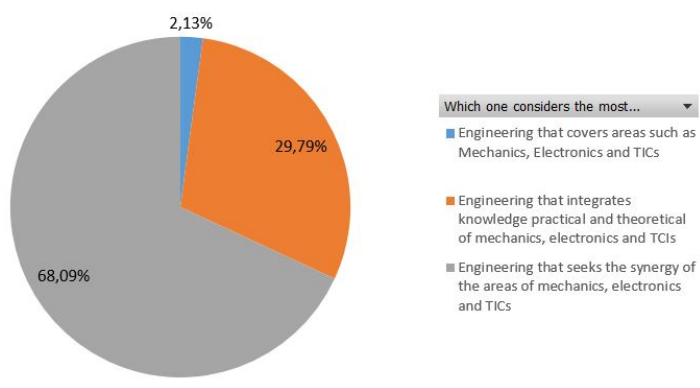

Fig. 8. Third Question.

It was also asked, what was considered as concept of mechatronics and $68.09 \%$ responded in a similar way, which is an engineering that seeks the synergy of the areas of mechanics, electronics and TIC in search of practical solutions for any kind of problems or as seen in the test: "Synergy between several engineering companies that considers the balance of knowledge necessary to develop advances within the integration between mechanical and electronic systems, taking into account those with the use of automated processes." while $29.79 \%$ considered that the Engineering integrated the knowledge of the areas of mechanics, electronics and ICTs in order to generate something innovative and the remaining $2.13 \%$ considered to cover mechanics, electronics and control.

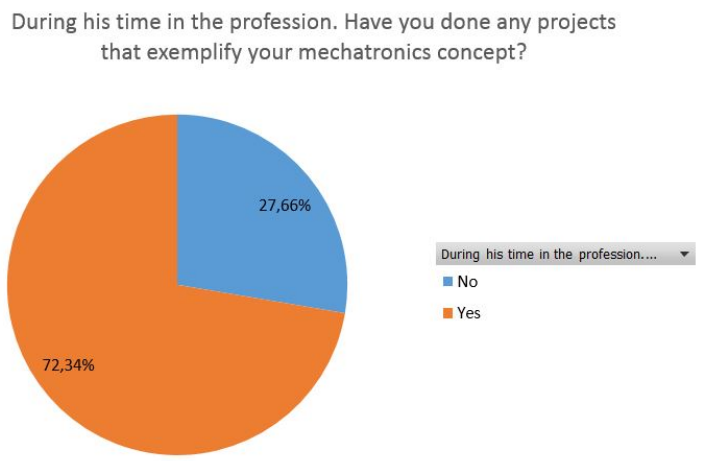

Fig. 9. Fourth Question.

As part of its development in the curricula, it was also consulted whether projects related to Mechatronics have been carried out, resulting in $71.7 \%$ of respondents doing so in subjects that are in the final levels of the study program, such as: Automation, Robotics, Instrumentation, Mechatronic Design among others; the remaining $29.7 \%$ has not carried out projects, being all students of the new curricula that are in the initial levels of the study program, although there are cases like third-semester students who have done projects in subjects such as: fundamentals of circuits or foundations of the Mechatronics that are the first subjects that are in charge of generating an integrating concept in the student.

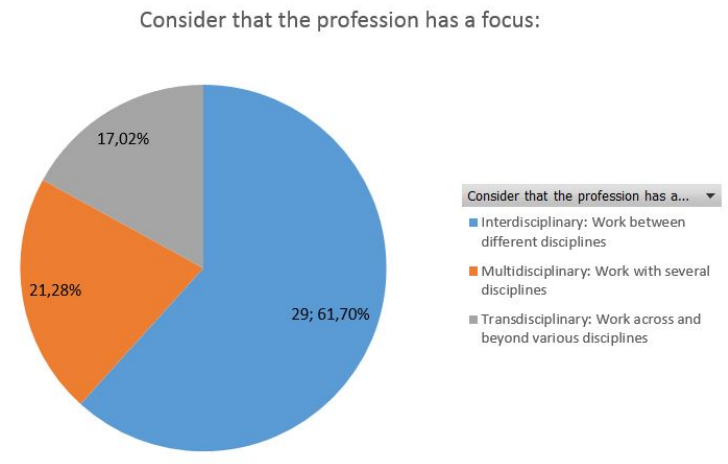

Fig. 10. Fifth Question.

Finally, the question arose as to which approach has the study program within the university on the relationship between the subjects, where it was obtained that 61.70 $\%$ of the respondents consider that their curricula have an interdisciplinary approach, $21.28 \%$ consider that It is Multidisciplinary, it is because the majority of respondents belong to the first curricula and $17.02 \%$ affirm that it is transdisciplinary, those who responded in this way belong to the second and third curricula.

\section{CONClusion}

The evolution of mechatronics was analyzed over 12 years through two updates of the Mechatronics Engineering studies program at the Universidad de las Fuerzas Armadas - ESPE. From the updates, 4 significant subjects have been obtained for their analysis: Introduction to Mechatronics, Integrating Projects, Mechatronics Instrumentation and Introduction to Cyber-Physical Systems. It was considered because they are key subjects in the process of student training in the first and third year of the career.

In each one of the subjects, the study cases corresponding to the 3 curricula that have been implemented were analyzed. In the analysis of the case studies, it was possible to clearly demonstrate the transformation process that the study program has undergone throughout the 12 years. It started with a multidisciplinary model with the first curricula and currently the trend with the third curricula is to arrive at a transdisciplinary approach. To validate the hypotheses proposed within the project, a test was developed for students and teachers who have participated throughout this evolution. With this it was possible to conclude that the evolution of the career along the three curricular designs is notorious. In the first case, the student was evaluated both theoretically and practically. This evaluation was carried out to ensure that the concepts taught were correctly assimilated. Within the practical part, the student's ability to provide a mechatronic solution that shows the different areas applied was evaluated. In the second case, it was analyzed how the student used the knowledge obtained in order to properly select the type of sensor to be used in the various applications for this the student should be able to identify the nature of each phenomenon

$1^{\text {th }}$ LACCEI International Multi-Conference for Engineering, Education, and Technology: "Industry, Innovation, And Infrastructure for Sustainable Cities and Communities", 24-26 July 2019, Jamaica. 
With the first change of curricula the way of evaluating was modified since the aim was for the student to identify and define how all the areas of engineering that make up the mechatronics were integrated. In the third case, it was taken into account how the students integrated the subjects they knew in order to solve the given problem. In a similar way for the fourth case, a system was used where a group of evaluators of the specific areas of mechanics and electronics were in charge of evaluating the projects presented by the students. In this case, the demonstration of the interdisciplinarity of the race was sought.

In order to evaluate the transdisciplinarity that is sought in the third curriculum, the tutor examines that the students demonstrate the existing synergy in the different areas of mechatronics. In the fifth case, the student uses the lego or tetrix kits to generate a solution in which one can appreciate how the synergy of the different fields of mechatronics can solve the same problem in different ways. Finally, in the sixth case, it is expected to be able to analyze how the use of the new technology generates a deeper interrelation between the disciplines studied.

The $68.09 \%$ of students and graduates support that the mechatronics is an engineering that seeks the synergy of the areas of mechanics, electronics and ICT in search of practical solutions for any type of problems and likewise $61.70 \%$ consider mechatronics it is an integration of the areas of mechanics, electronics and ICTs. Similarly, $61.70 \%$ of respondents consider that their curricula have an interdisciplinary approach and $17.02 \%$ that is transdiciplinary, which shows that the career is in a state of evolution since the last percentage belongs in its majority to students of the third curricula and the last levels of the second curriculum.
[12] F. Mendoza Moreira, T. González Palacios,'Fuentes epistemológicas y contextuales para la generación de currículos pertinentes en la sociedad del conocimiento", FORO EDUCACIONAL N $N^{o}$ 24, pp. 11-33, 2015.

[13] J. Núñez Mejía, Resolución 2006-026-ESPE-a-3, Escuela Politécnica del Ejército, Sangolquí, 2006.

[14] D. González, A. Verdugo, L. Escobar, D. Loza, "Implementation of an IoT Architecture based on MQTT for a Multi-Robot System" IEEE Third Ecuador Technical Chapters Meeting (ETCM), Cuenca, 2018.

[15] E. Serrano, E. Pérez, E. Aguilar, L. Escobar, N. Pinto, "Design of a Spatial Disorientation Simulator using a Modified Stewart-Gough Platform" IEEE Third Ecuador Technical Chapters Meeting (ETCM), Cuenca, 2018

[16] R. Vargas, Diseño Curricular por Competencias, ANFEI, México, 2018.

[17] R. Moreira Cedeño, Resolución ESPE-HCU-RES-2016-073, Universidad de las Fuerzas Armadas - ESPE, Sangolquí, 2016.

[18] Álvarez Peña, C. Neff, F. J. Moya Rodríguez, J. L. Chagoyén Méndez, C. A. Machado Rodríguez, Teaching Mechatronics engineering a challenge of the new century, The 2nd International Symposium on Integrating Research, Education, and Problem Solving. Orlando, Florida USA.

[19] Aquino J.A., Corona L. Fernández C., La Formación Integral en Ingeniería Mecatrónica, VI Congreso Internacional de Ingeniería Electromecánica y de Sistemas IPN- ESIME-SEPI México D.F. noviembre del 2011.

[20] Aquino J.A., Corona L., Fernández C., Cuervo V.D., Trayectoria evolutiva de los criterios de evaluación en la enseñanza de la ingeniería Mecatrónica, IV Foro Nacional de Ciencias Básicas, organizado por la división de ciencias básicas de la Facultad de Ingeniería de la UNAM. México, Octubre de 2010.

[21] Bishop H. Robert, The Mechatronics Handbook, CRC Press. Oustin Texas, 2002.

\section{ACKNOWLEDGMENT}

\section{REFERENCES}

[1] R. Comerford, "Mechatronics... What?," IEEE Spectrum, pp. 46 49, 1994

[2] Kyura, N. and Oho, H., "Mechatronics - an industrial perspective," IEEE/ASME Transactions on Mechatronics., vol. 1, no. 1, pp. 10-15, 1996.

[3] T. Mori, "Yasakawa Internal Trademark Application”, Yasakawa, 1969.

[4] Rietdijk .A, "Ten propositions on mechatronics, Mechatronics in Products and Manufacturing Conference," Lancenter, England, 1989.

[5] K. Craig, "Mechatronics with Labview," Rensselaer Polytechnic Institute. USA.

[6] M. Grimheden, M. Hanson, "What is Mechatronics? Proposing a Didactical Approach to Mechatronics. Proceedings 1st Baltic See Workshop on Education in Mechatronics" Solid State Radio Engineering, Kiel, Germany, 2001

[7] “VDI-2206, Design methodology for mechatronic systems,"Düsseldorf, 2014.

[8] Ulrich, K., "Diseño y desarrollo de productos," Eppinger, México: McGrawHill, 2013.

[9] M. Grimheden, M. Hanson,'Mechatronics - the Evolution of an Academic Discipline in Engineering Education"Mechatronics 15, pp. 179-192, 2005.

[10] G. Pop, V. Maties,"A Transdisciplinary Approach to Knowledge in Mechatronical Education" Emmanuel University Oradea and Technical University Cluj-Napoca, Romania.

[11] K. Craig,"Mechatronics with Labview" Rensselaer Polytechnic Institute, USA.

17 $7^{\text {th }}$ LACCEI International Multi-Conference for Engineering, Education, and Technology: "Industry, Innovation, And Infrastructure for Sustainable Cities and Communities", 24-26 July 2019, Jamaica. 